\title{
Distortion/interaction analysis of the reactivities and selectivities of halo- and methoxy-substituted carbenes with alkenes
}

\author{
C. Avery Sader and K. N. Houk* \\ Department of Chemistry and Biochemistry, University of California, Los Angeles, \\ California $90095-1569$, U. S. A. \\ E-mail: houk@chem.ucla.edu
}

Dedicated to Pierre Vogel, a great scientist and friend, on his $\mathbf{7 0}^{\text {th }}$ birthday

DOI: $\underline{\text { http://dx.doi.org/10.3998/ark.5550190.p008.408 }}$

\begin{abstract}
The transition structures for the $(2+1)$ cycloadditions of dichlorocarbene, chlorofluorocarbene, and difluorocarbene to cyclohexene, 1 -hexene, ethylene, and $\alpha$-chloroacrylonitrile were located using quantum mechanical methods (M06-2X). In addition, transition structures for the $(2+1)$ cycloadditions of chloromethoxycarbene, fluoromethoxycarbene, and dimethoxycarbene to ethylene and $\alpha$-chloroacrylonitrile were computed. Except for the reactions with ethylene, these cycloadditions were studied experimentally and computationally by Moss and Krogh-Jespersen (Zhang, M.; Moss, R. A.; Thompson, J.; Krogh-Jespersen, K. J. Org. Chem. 2012, 77, 843-850). As a complement to the work of those groups, we have utilized the distortion/interaction model to understand reactivities and selectivities. Gas-phase calculations were carried out at the M062X/6-31+G(d,p) level of theory.
\end{abstract}

Keywords: Carbenes, cycloadditions, distortion interaction model, density functional theory

\section{Introduction}

The cycloadditions of carbenes to alkenes constitute a general method for synthesis of cyclopropane ring structures. These cycloadditions have excited widespread interest in the mechanistic details of this reaction. Hoffmann predicted that a $\mathrm{C}_{2 \mathrm{v}}$ cyclic four-electron transition state in which both $\mathrm{C}-\mathrm{C}$ bonds form simultaneously is orbital-symmetry forbidden, ${ }^{1,2}$ therefore, non-least motion approach was proposed by Hoffmann ${ }^{2}$ and Moore $^{3}$ in which there is initial interaction of the electrophilic empty $p$-orbital (LUMO) of the carbene with the nucleophilic filled $\pi$-orbital (HOMO) of the alkene. ${ }^{1}$ This prediction was subsequently verified many times with semiempirical ${ }^{4-6}$ and ab initio methods ${ }^{7,8}$ and was shown to be influenced by a second pair of orbital interactions between the lone pair (HOMO) of the carbene with the $\pi^{*}$ antibonding 
orbital (LUMO) of the alkene, which becomes dominant for electron-donor substituted carbenes. $^{8}$

Carbene cycloadditions have been extensively studied experimentally and computationally by the groups of Moss and Krogh-Jespersen over the last decade. ${ }^{9-12}$ They combined laser flash photolysis and density functional theory calculations to determine activation parameters for a series of carbene cycloadditions. ${ }^{13}$ They found that trends in $\Delta E^{t}$ parallel expectations based on considerations of carbene stability and nucleophilicity. As a complement to the work of those groups, we have computationally investigated the $(2+1)$ cycloadditions of dihalocarbenes 1a-c to cyclohexene (2a) and 1-hexene (2b), as well as the cycloadditions of 1a-c and methoxycarbenes 1d-f to ethylene (2c) and $\alpha$-chloroacrylonitrile (2d) in the context of the distortion/interaction model of reactivity developed by our group ${ }^{14}$ (or the activation-strain model developed independently by Bickelhaupt). ${ }^{15}$

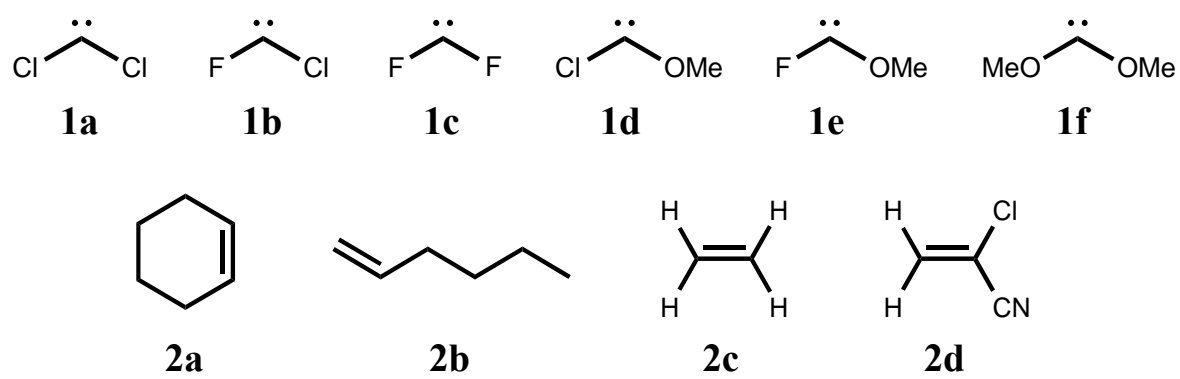

Figure 1. The carbenes and alkenes employed in this computational study. All except $\mathbf{2 c}$ have been studied experimentally and computationally by Moss and Krogh-Jespersen. ${ }^{13}$

\section{Computational Methodology}

Gas phase reactant, product, and transition state geometry optimizations as well as analytical frequencies were computed using the hybrid meta-GGA functional M06-2X ${ }^{16}$ with the 6$31+\mathrm{G}(\mathrm{d}, \mathrm{p})$ basis set in the Gaussian 09 suite of programs. ${ }^{17}$ Tight convergence criteria and an ultrafine integration grid were used in all optimizations. All reactants have positive definite Hessian matrices and all transition structures have only one negative eigenvalue in their diagonalized force constant matrices. Intrinsic reaction coordinate (IRC) ${ }^{18,19}$ calculations were performed to obtain a potential energy surface for distortion/interaction analysis and to ensure that all optimized transition structures connect the appropriate reactants and products.

\section{Results and Discussion}

The distortion/interaction model developed by our group has recently been applied to explain the reactivities and selectivities of $(3+2)$ cycloadditions. ${ }^{14}$ This model dissects activation barriers 
$\left(\Delta E^{f}\right)$ of bimolecular reactions into distortion energies $\left(\Delta E_{d} \dot{t}\right)$ and interaction energies $\left(\Delta E_{i}^{f}\right)$. The distortion energy is the amount of energy required to distort the carbenes and alkenes into their transition state geometries without allowing the cycloaddition partners to interact. The interaction energy arises from a combination of closed-shell repulsion, charge transfer involving occupied and vacant orbital interactions, electrostatic interactions, and polarization effects. By definition, $\Delta E^{t}=\Delta E_{d^{t}}^{t}+\Delta E_{i}^{t}$, and the position of the transition state occurs at the point along the reaction coordinate, $\zeta$, where the derivatives of the distortion and interaction energies are equal and opposite $\left(\delta \Delta E_{d}(\zeta) / \delta \zeta=-\delta \Delta E_{i}(\zeta) / \delta \zeta\right)$. Figure 2 shows the transition structures for the cycloadditions of $\mathbf{1 a - c}$ with $\mathbf{2 a}$ and $\mathbf{2 b}$ and $\mathbf{1 a - f}$ with $\mathbf{2 c}$ and $\mathbf{2 d}$ computed with M06-2X/6$31+G(d, p)$. Table 1 shows the activation and total distortion energies, the contributions to the distortion energies of the carbene and the alkene, and the interaction energies for reactions of 1a$\mathbf{c}$ with $\mathbf{2 a}$ and $\mathbf{2 b}$ and $\mathbf{1 a}-\mathbf{f}$ with $\mathbf{2 c}$ and $\mathbf{2 d}$.

Table 1. Distortion/interaction energies (in $\mathrm{kcal} \mathrm{mol}^{-1}$ ) for cycloaddition transition structures computed at the M06-2X/6-31+G(d,p) level

\begin{tabular}{|c|c|c|c|c|c|c|}
\hline Carbene & Alkene & $\Delta E^{\not t}$ & $\Delta E_{d^{+}}$total & $\Delta E_{d^{*}}$ carbene & $\Delta E_{d^{t}}^{t}$ alkene & $\Delta E_{i}^{t}$ \\
\hline $\mathrm{CCl}_{2}$ & c-Hex & -4.1 & 2.6 & 1.5 & 1.1 & -6.7 \\
\hline $\mathrm{CClF}$ & c-Hex & -1.3 & 5.3 & 2.0 & 3.3 & -6.6 \\
\hline $\mathrm{CF}_{2}$ & c-Hex & 7.4 & 9.2 & 2.6 & 6.6 & -1.8 \\
\hline $\mathrm{CCl}_{2}$ & 1-Hex & -3.3 & 1.5 & 0.9 & 0.6 & -4.8 \\
\hline $\mathrm{CClF}$ & 1-Hex & -0.9 & 3.4 & 1.5 & 1.9 & -4.3 \\
\hline $\mathrm{CF}_{2}$ & 1-Hex & 6.4 & 7.3 & 2.0 & 5.3 & -0.9 \\
\hline $\mathrm{CCl}_{2}$ & $\mathrm{C}_{2} \mathrm{H}_{4}$ & 0.1 & 1.7 & 0.8 & 0.9 & -1.6 \\
\hline $\mathrm{CClF}$ & $\mathrm{C}_{2} \mathrm{H}_{4}$ & 3.3 & 3.1 & 1.2 & 1.9 & 0.2 \\
\hline $\mathrm{CF}_{2}$ & $\mathrm{C}_{2} \mathrm{H}_{4}$ & 10.3 & 5.8 & 1.5 & 4.3 & 4.5 \\
\hline ClCOMe & $\mathrm{C}_{2} \mathrm{H}_{4}$ & 8.4 & 6.9 & 3.4 & 3.5 & 1.5 \\
\hline FCOMe & $\mathrm{C}_{2} \mathrm{H}_{4}$ & 13.1 & 8.7 & 3.5 & 5.2 & 4.4 \\
\hline $\mathrm{C}(\mathrm{OMe})_{2}$ & $\mathrm{C}_{2} \mathrm{H}_{4}$ & 16.2 & 10.3 & 3.3 & 7.0 & 6.0 \\
\hline $\mathrm{CCl}_{2}$ & $\alpha-\mathrm{ClACN}$ & -3.2 & 1.3 & 0.0 & 1.3 & -4.5 \\
\hline $\mathrm{CClF}$ & $\alpha-\mathrm{ClACN}$ & 0.0 & 2.5 & 0.2 & 2.3 & -2.5 \\
\hline $\mathrm{CF}_{2}$ & $\alpha-\mathrm{ClACN}$ & 5.4 & 5.0 & 0.4 & 4.6 & 0.3 \\
\hline ClCOMe & $\alpha-\mathrm{ClACN}$ & 0.0 & 4.8 & 0.9 & 3.9 & -4.8 \\
\hline FCOMe & $\alpha-\mathrm{ClACN}$ & 3.4 & 6.1 & 1.0 & 5.1 & -2.7 \\
\hline $\mathrm{C}(\mathrm{OMe})_{2}$ & $\alpha-\mathrm{ClACN}$ & 1.2 & 7.9 & 2.3 & 5.6 & -6.7 \\
\hline
\end{tabular}



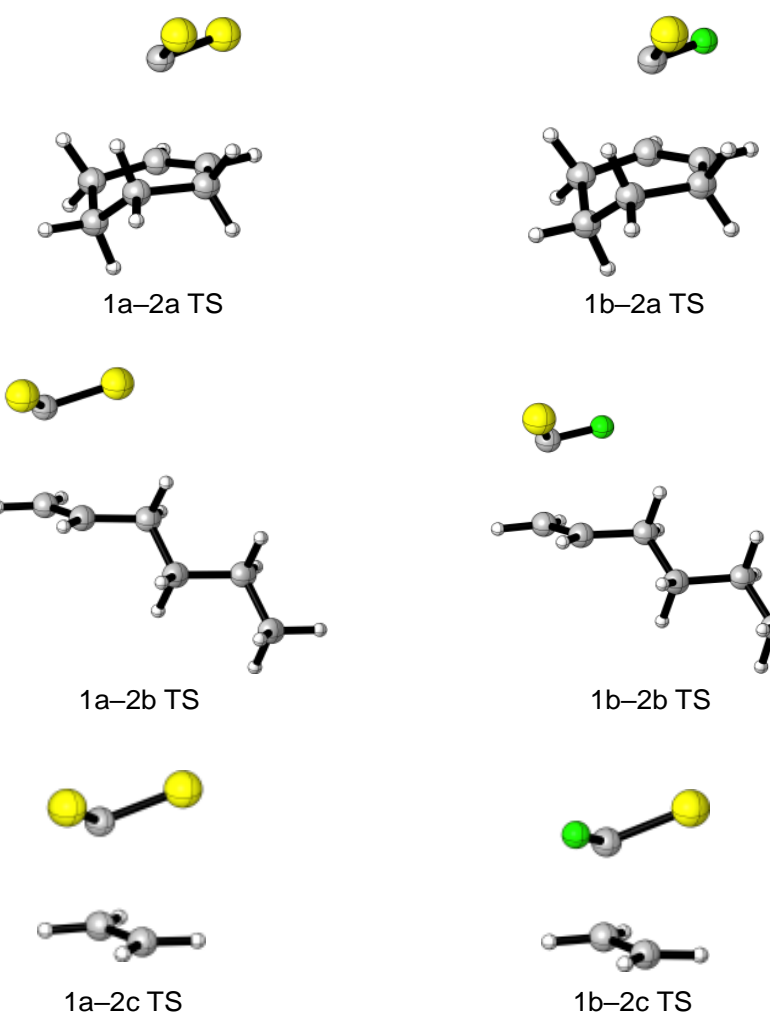

1b-2a TS

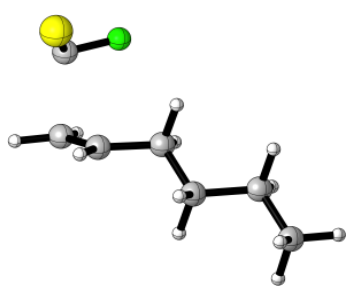

$1 b-2 b$ TS
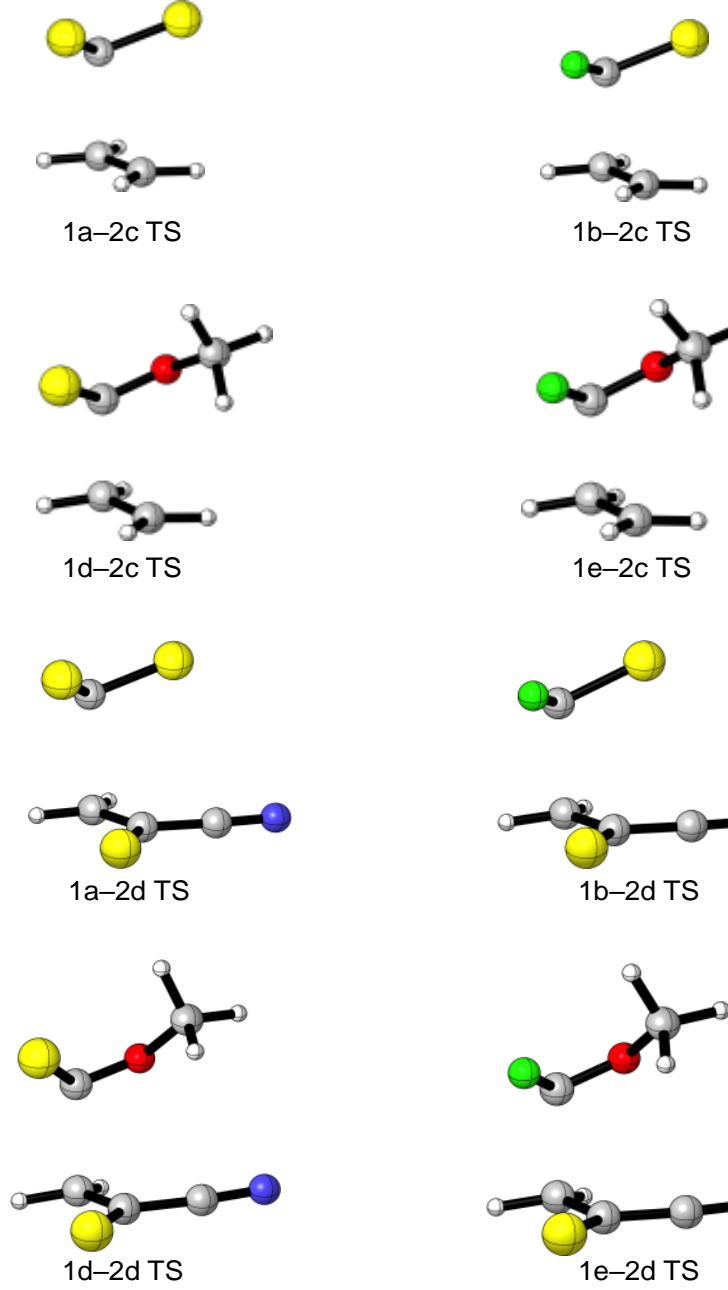
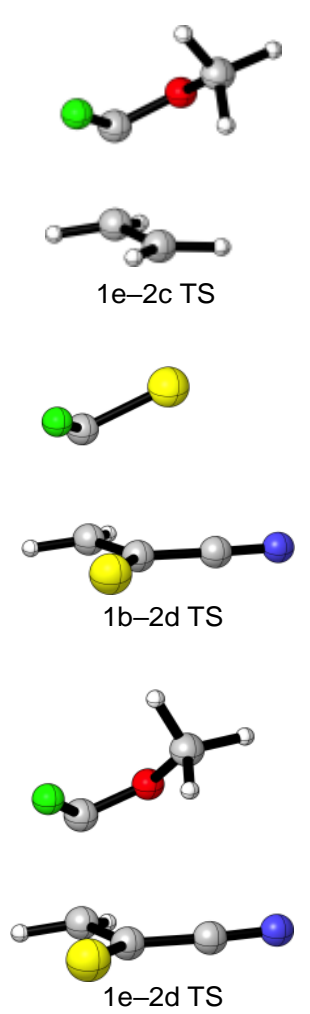
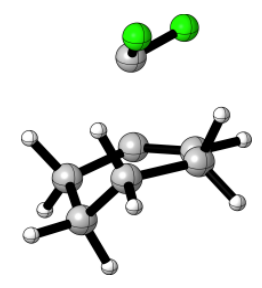

$$
\text { 1c-2a TS }
$$

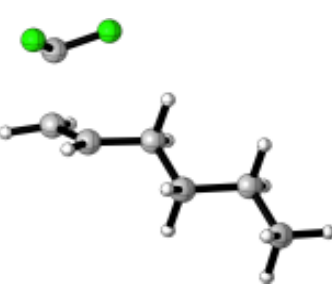

$1 c-2 b$ TS
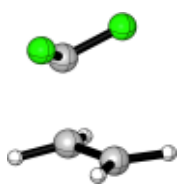

1c-2c TS
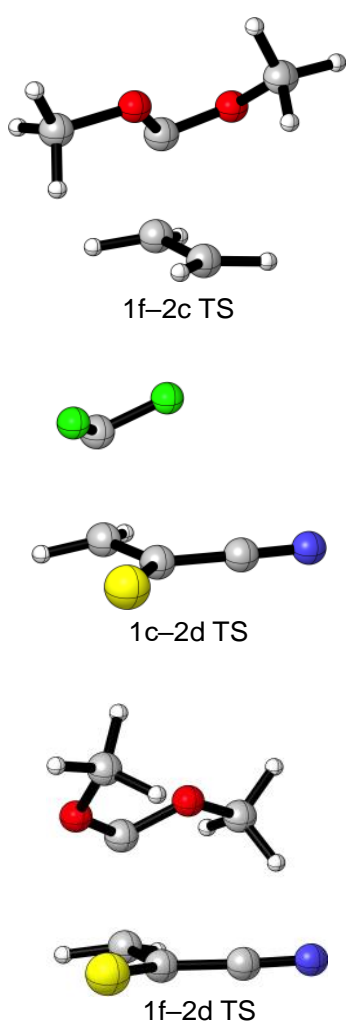

Figure 2. Optimized transition structures for the 18 cycloadditions in this study computed at the M06-2X/6-31+G(d,p) level. Geometrical parameters are given in Table 2. 


\section{Cycloadditions to cyclohexene and 1-hexene}

As shown in Table 1, the cycloadditions of $\mathrm{CCl}_{2}$ (1a) and $\mathrm{CClF}(\mathbf{1 b})$ to cyclohexene (2a) and 1hexene (2b) have negative activation energies, which are controlled by $\Delta E_{i}^{t}$. We found that favorable interaction energy contributes to negative $\Delta E$ at intermediate separation of the carbenes and alkenes studied here and suggests the formation of carbene-alkene precursor complexes, although the existence of these has been debated in the literature. ${ }^{20-29}$ We have confirmed $\pi-$ complexes for cycloadditions to $\mathbf{2 a}, \mathbf{2 b}$, and $\mathbf{2 d}$ that are stabilized by $0-5 \mathrm{kcal} \mathrm{mol}^{-1}\left(\Delta H^{\mathrm{o}}=\right.$ $\left.\Delta H_{\text {free }} e^{*}-\Delta H_{\text {complex }}{ }^{*}\right)$ relative to infinitely separated reactants; however, they are not minima on the free energy surface and thus are not expected to be experimentally stable. These computed activation energies are 6-8 kcal/mol too low when compared to activation energies determined experimentally by Moss and Krogh-Jespersen; ${ }^{13}$ therefore, conclusions from these results should be taken with caution. An increase of 6-7 kcal mol${ }^{-1}$ in the distortion energies and a decrease of 4-5 kcal mol ${ }^{-1}$ in the favorable (negative) interaction energies results in a substantial increase of the activation energies along the series $\mathbf{1 a} \rightarrow \mathbf{1 b} \rightarrow \mathbf{1 c}$. The carbene and alkene contributions to the total distortion energies for $\mathbf{1 a}$ and $\mathbf{1 b}$ are within $\sim 1 \mathrm{kcal} \mathrm{mol}^{-1}$. As for reactions of $\mathrm{CF}_{2}(\mathbf{1 c})$, distortion of the alkene is the primary cause of the increase in $\Delta E_{d^{t}}$, as seen in an average $\Delta \Delta E_{d, \text { carbene }} e^{+}$of $1.1 \mathrm{kcal} \mathrm{mol}^{-1}$ and $\Delta \Delta E_{\text {d,alkene }}{ }^{+t}$ of $5.1 \mathrm{kcal} \mathrm{mol}^{-1}$ relative to $1 \mathrm{a}$. Distortion of cyclohexene and 1-hexene comprises $42-72 \%$ and $40-73 \%$, respectively, of the total distortion energy. In Table 2, the alkene bond distances, $r_{13}$, increase by a mere $0.02-0.03 \AA$ from $\mathbf{1 a} \rightarrow \mathbf{1 b} \rightarrow \mathbf{1 c}$; therefore, $\mathrm{C} 1-\mathrm{C} 3$ bond elongation is not a significant contributor to $\Delta \Delta E_{d}^{t}$. We use angles $\alpha$ and $\beta$ to quantify the degree of pyramidalization of the terminal alkene carbons. As shown in Table $2, \alpha$ increases by $17^{\circ}$ and $\beta$ increases by $6^{\circ}$ along the series $\mathbf{1 a} \rightarrow \mathbf{1 b} \rightarrow \mathbf{1 c}$. A greater extent of pyramidalization at $\mathrm{C} 3$ of the alkene occurs as a result of non-least motion approach in which the $\mathrm{C} 2-\mathrm{C} 3$ bond forms before the $\mathrm{C} 2-\mathrm{C} 1$ bond. We conclude that pyramidalization of the alkene carbons is the major distortion occurring at the transition state, and the change in $\mathrm{C} 1-\mathrm{C} 3$ bond length occurs mainly after the transition state. An increase in the values of $\alpha$ and $\beta$ indicates progressively later transition states and greater nucleophilic character of the carbene. The distance between $\mathrm{C} 2$ and the midpoint of the alkene $(d)$ as well as the forming bond distances ( $r_{12}$ and $r_{23}$ ) become shorter along the same series $\mathbf{1 a} \rightarrow \mathbf{1 b} \rightarrow \mathbf{1 c}$, which also supports later transition states and increasing $\Delta E_{d^{t}}^{t}$.

Based on the values of the carbene tilt angle $\gamma$ in Table $2,{ }^{8} \mathbf{1 a}-\mathbf{c}$ react as electrophilic carbenes toward electron-rich alkenes $\mathbf{2 a}$ and $\mathbf{2 b}$. Increasing carbene LUMO energies $\left(\mathrm{CCl}_{2}\right.$ : $-3.74 \mathrm{eV}$; CClF: $\left.-3.39 \mathrm{eV} ; \mathrm{CF}_{2}:-2.83 \mathrm{eV}\right)^{13}$ lead to decreased interaction with the $\pi$-orbitals of $\mathbf{2 a}$ and $\mathbf{2 b}$, which is likely one factor that attributes to a higher $\Delta E_{i}^{t}$ for $\mathbf{1 c}$. However, since $\Delta E_{i}^{+}$ for $\mathbf{1 a}$ and $\mathbf{1 b}$ are essentially identical, there must be a complex interplay of factors that render this analysis of $\Delta \Delta E_{i}^{t}$ incomplete. An energy decomposition analysis would be required for any greater insight into the physical origins of $\Delta E_{i}^{t}$. 
Table 2. Geometrical parameters of the cycloaddition transition structures computed at the M06-2X/6-31+G(d,p) level. Distances are in $\AA$ and angles are in degrees

\begin{tabular}{|c|c|c|c|c|c|c|c|c|c|}
\hline Carbene & Alkene & $r_{12}$ & $r_{23}$ & $d$ & $r_{13}$ & $\angle \mathrm{XCY}$ & $\alpha$ & $\beta$ & $\gamma$ \\
\hline $\mathrm{CCl}_{2}$ & c-Hex & 2.60 & 2.28 & 2.35 & 1.36 & 108 & 9 & 1 & 31 \\
\hline $\mathrm{CClF}$ & c-Hex & 2.41 & 1.99 & 2.10 & 1.37 & 105 & 18 & 2 & 35 \\
\hline $\mathrm{CF}_{2}$ & c-Hex & 2.29 & 1.81 & 1.94 & 1.38 & 104 & 26 & 7 & 39 \\
\hline $\mathrm{CCl}_{2}$ & 1-Hex & 2.79 & 2.34 & 2.49 & 1.35 & 108 & 6 & 3 & 35 \\
\hline $\mathrm{CClF}$ & 1-Hex & 2.51 & 2.06 & 2.19 & 1.36 & 104 & 13 & 6 & 35 \\
\hline $\mathrm{CF}_{2}$ & 1-Hex & 2.39 & 1.81 & 2.01 & 1.38 & 104 & 23 & 9 & 41 \\
\hline $\mathrm{CCl}_{2}$ & $\mathrm{C}_{2} \mathrm{H}_{4}$ & 2.63 & 2.18 & 2.32 & 1.35 & 109 & 9 & 3 & 40 \\
\hline $\mathrm{CClF}$ & $\mathrm{C}_{2} \mathrm{H}_{4}$ & 2.46 & 2.00 & 2.14 & 1.36 & 106 & 15 & 5 & 39 \\
\hline $\mathrm{CF}_{2}$ & $\mathrm{C}_{2} \mathrm{H}_{4}$ & 2.37 & 1.84 & 2.00 & 1.37 & 105 & 22 & 8 & 44 \\
\hline $\mathrm{ClCOMe}$ & $\mathrm{C}_{2} \mathrm{H}_{4}$ & 2.47 & 1.92 & 2.10 & 1.37 & 113 & 20 & 4 & 48 \\
\hline FCOMe & $\mathrm{C}_{2} \mathrm{H}_{4}$ & 2.42 & 1.84 & 2.04 & 1.38 & 110 & 24 & 5 & 50 \\
\hline $\mathrm{C}(\mathrm{OMe})_{2}$ & $\mathrm{C}_{2} \mathrm{H}_{4}$ & 2.45 & 1.83 & 2.05 & 1.39 & 111 & 28 & 7 & 57 \\
\hline $\mathrm{CCl}_{2}$ & $\alpha-\mathrm{ClACN}$ & 2.82 & 2.29 & 2.48 & 1.35 & 110 & 11 & 5 & 42 \\
\hline $\mathrm{CClF}$ & $\alpha-\mathrm{ClACN}$ & 2.65 & 2.11 & 2.30 & 1.36 & 107 & 16 & 6 & 41 \\
\hline $\mathrm{CF}_{2}$ & $\alpha-\mathrm{ClACN}$ & 2.52 & 1.93 & 2.14 & 1.37 & 106 & 24 & 8 & 44 \\
\hline ClCOMe & $\alpha-\mathrm{ClACN}$ & 2.63 & 2.04 & 2.25 & 1.37 & 114 & 21 & 8 & 50 \\
\hline FCOMe & $\alpha-\mathrm{ClACN}$ & 2.56 & 1.96 & 2.17 & 1.38 & 111 & 24 & 10 & 49 \\
\hline $\mathrm{C}(\mathrm{OMe})_{2}$ & $\alpha-\mathrm{ClACN}$ & 2.64 & 2.01 & 2.24 & 1.38 & 112 & 25 & 11 & 55 \\
\hline
\end{tabular}

\section{Cycloadditions to ethylene}

In addition to the distortion/interaction analyses for the TS that are collected in Table 1, the reaction profiles together with their decomposition into $\Delta E_{d}$ and $\Delta E_{i}$ for cycloadditions of dihalocarbenes 1a-c and methoxycarbenes 1d-f to ethylene (2c) are shown in Figure 3. Plots of $\Delta E_{d}$ and $\Delta E_{i}$ for all cycloadditions to $\mathbf{2 c}$ are shown in Figures 4 and 5, respectively. 

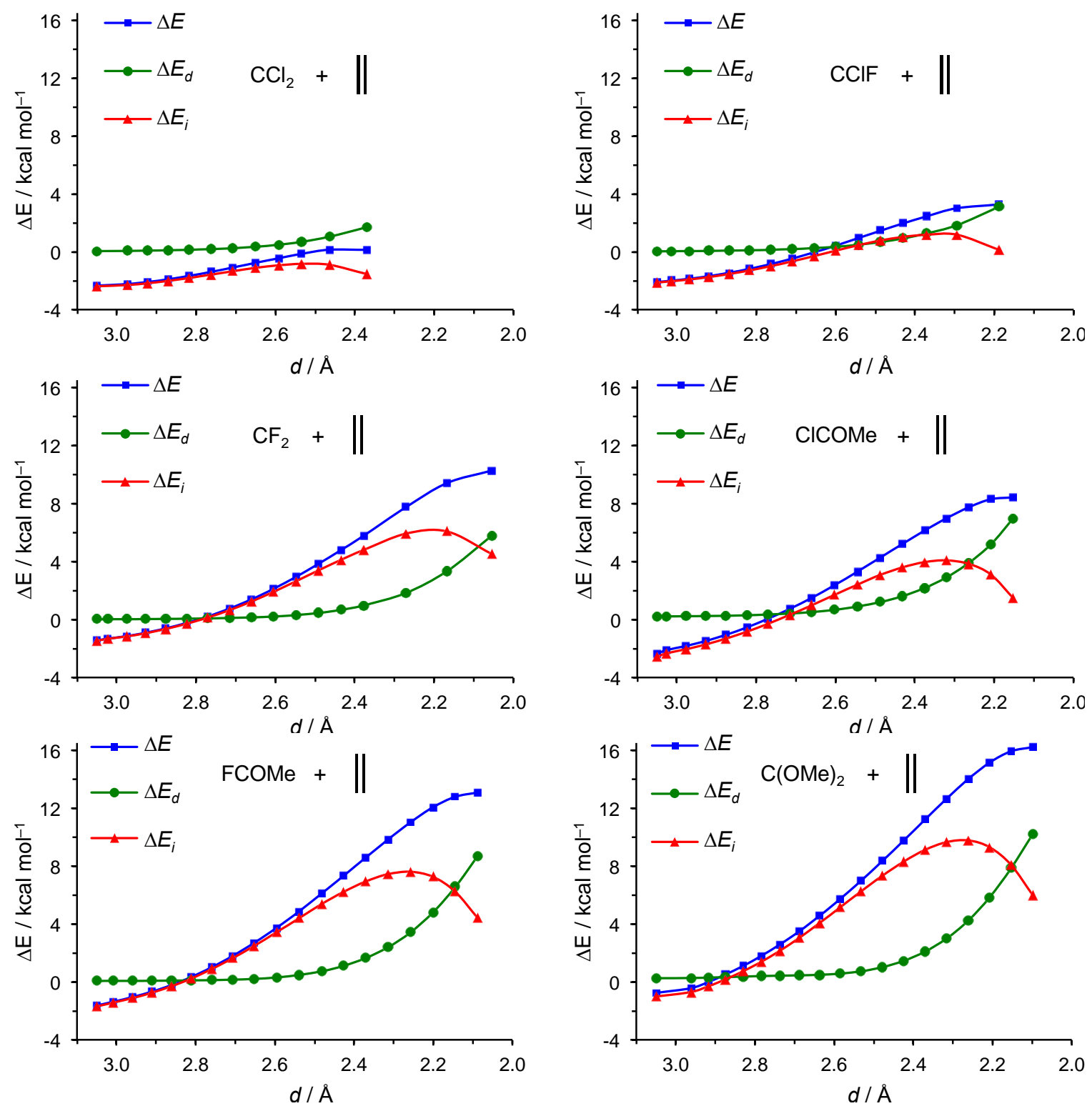

Figure 3. Distortion/interaction analysis of the $(2+1)$ cycloaddition reaction between carbenes $\mathbf{1 a}-\mathbf{f}$ and $2 \mathbf{c}$ projected onto the distance between $\mathrm{C} 2$ and the midpoint of ethylene (in $\AA$ ). All data have been computed at the M06-2X/6-31+G(d,p) level. 


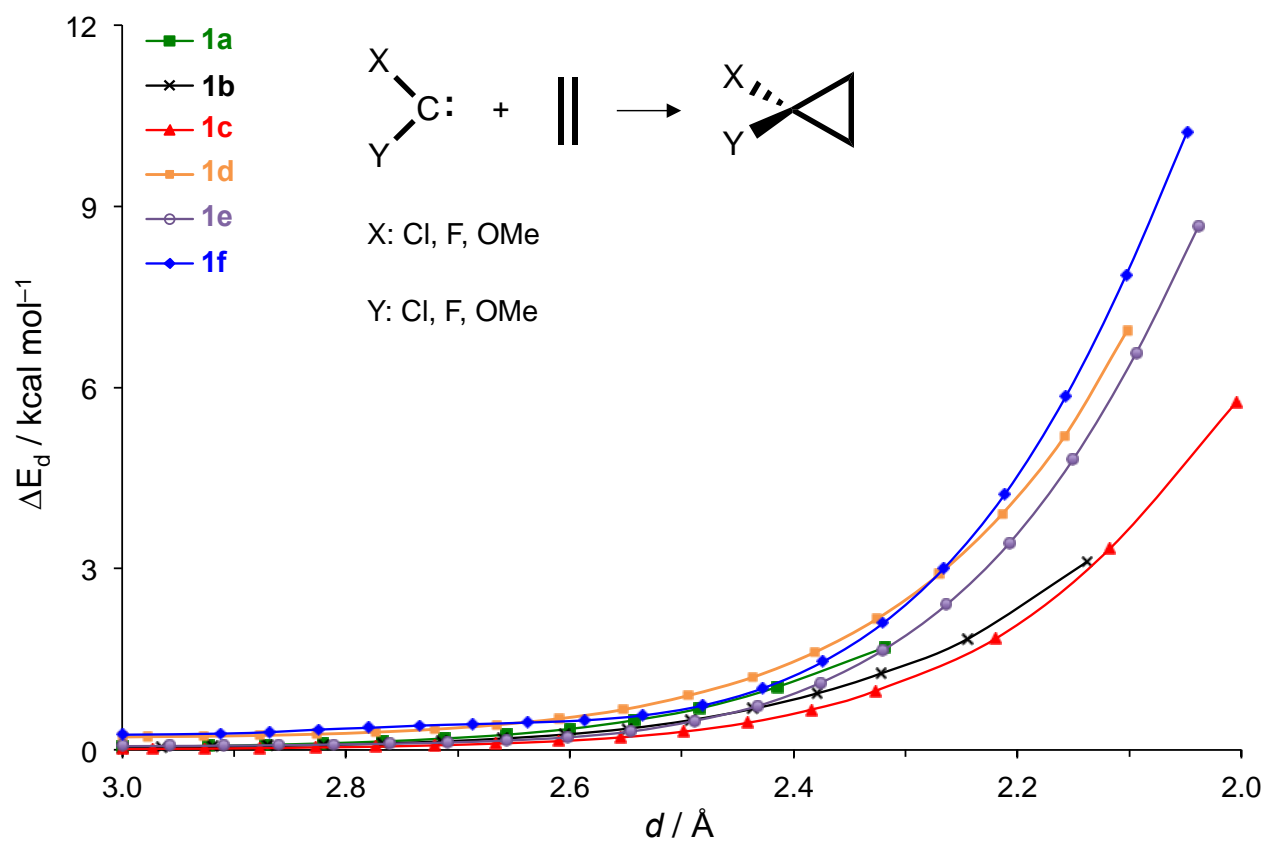

Figure 4. Distortion energy profiles of carbene cycloadditions to ethylene.

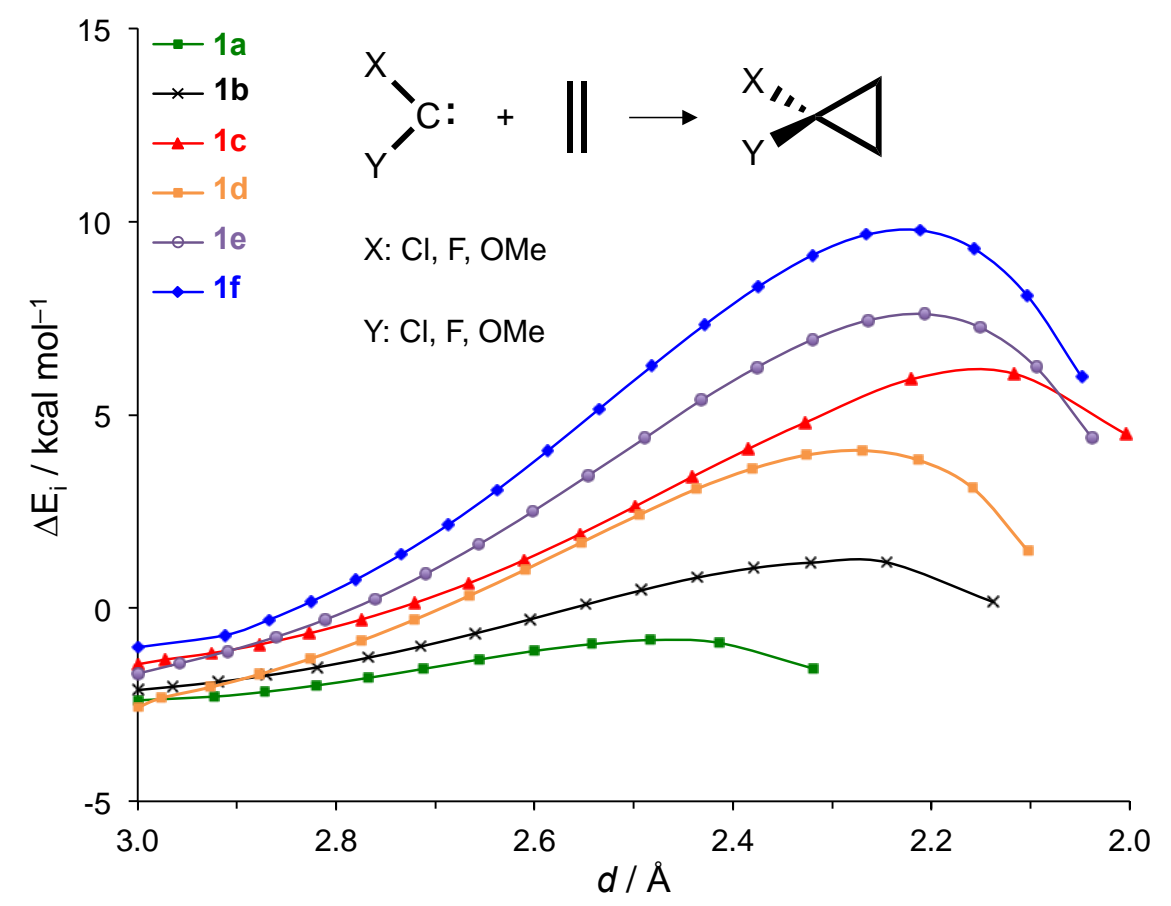

Figure 5. Interaction energy profiles of carbene cycloadditions to ethylene.

Activation energies for cycloadditions of 1a-c and 1d-f to $2 \mathbf{c}$ increase from 0-10 and 8-16 kcal mol ${ }^{-1}$, respectively. Changes in $\Delta E_{d^{t}}^{t}$ and $\Delta E_{i}^{t}$ are comparable in magnitude, and both contribute to an increase in $\Delta E^{\ddagger}$ from $\mathbf{1 a} \rightarrow \mathbf{1 b} \rightarrow \mathbf{1 c}$ and from $\mathbf{1 d} \rightarrow \mathbf{1 e} \rightarrow \mathbf{1 f}$. The distortion of 
ethylene comprises $51-74 \%$ of the total distortion energy. Carbene tilt angles in Table 2 indicate that $\mathbf{1 a}-\mathbf{c}$ are predominantly electrophilic and $\mathbf{1 d - \mathbf { f }}$ are predominantly nucleophilic in cycloadditions to $\mathbf{2 c}$. All interaction energies for the reactions with $\mathbf{2 c}$ are positive except for that of 1a, resulting in activation barriers greater than the inherent distortion in the transition structures. This result differs from those seen for example in 1,3-dipolar and Diels-Alder cycloadditions, where the interaction energies at the transition states are negative, i.e., favorable, in all cases such that the activation barrier is decreased relative to the distortion energy. ${ }^{30}$ The alkyl substituents of $\mathbf{2 a}$ and $\mathbf{2 b}$ raise the $\mathrm{HOMO}$ of ethylene while the $-\mathrm{Cl}$ and $-\mathrm{CN}$ substituents of $2 \mathbf{d}$ lower the LUMO of ethylene. Both of these perturbations decrease the frontier molecular orbital gaps between the carbene and alkene and lead to favorable interaction energies with respect to ethylene. Previously reported trends in HOMO and LUMO energies for these alkenes support this conclusion. ${ }^{13}$ This trend in reactivity has been documented in the literature for other bimolecular reactions. ${ }^{31-35}$ Houk and Ess examined cycloadditions of hydrazoic acid, an ambiphilic 1,3-dipole, to a series of substituted alkenes and found that electron-rich and

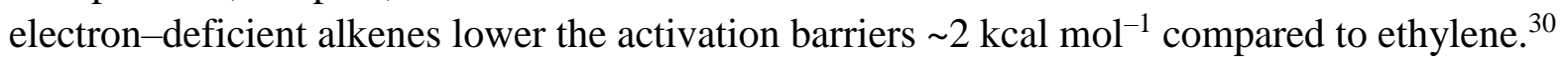

From the distortion/interaction analyses in Figure 3, medium-range $(d \sim 3 \AA)$ attractive interactions exist while there is yet no distortion between the carbene and ethylene. This results in a negative $\Delta E$ relative to infinitely separated reactants and indicates formation of $\pi$-complexes, as mentioned earlier. In all cycloadditions to ethylene, there is no substantial increase in $\Delta E_{d}$ while $\mathrm{d}>2.4 \AA$ (Figure 3 ); therefore, the rise in $\Delta E$ along the reaction coordinate is primarily due to an increasingly destabilizing interaction between the carbene and the alkene. The early inversion of $\Delta E_{i}$ from destabilizing to stabilizing in $\mathbf{1 a}$ is responsible for a particularly early transition state. This behavior seems to be general to pericyclic reactions as it has been observed by Bickelhaupt in $(3+2)$ cycloadditions, ${ }^{36}$ Alder-ene reactions, ${ }^{37}$ and double group-transfer reactions. ${ }^{38}$ Bickelhaupt has also pointed out that the initially destabilizing $\Delta E_{i}$ observed in pericyclic reactions contrasts those seen in other bimolecular reactions such as $\mathrm{S}_{\mathrm{N}} 2$ substitution ${ }^{39}$ and E2 elimination. ${ }^{40}$

\section{Cycloadditions to $\alpha$-chloroacrylonitrile}

The same general increase in $\Delta E^{*}$ from $\mathbf{1 a} \rightarrow \mathbf{1 b} \rightarrow \mathbf{1} \mathbf{c}$ is observed with $\alpha$-chloroacrylonitrile as in additions to $\mathbf{2 a}-\mathbf{c}$ due to increased stabilization of the carbene by fluorine substituents. The distortion of $\alpha$-chloroacrylonitrile (2d) is the dominant factor of $\Delta E_{d^{t}}$, comprising $71-100 \%$ of the total distortion energy in the transition state. The activation energy of $\mathbf{1 a}$ addition to $\mathbf{2 d}$ is negative due to a favorable interaction energy of $4.5 \mathrm{kcal} \mathrm{mol}^{-1}$ that compensates for the $1 \mathrm{kcal}$ $\mathrm{mol}^{-1}$ distortion energy of $\mathbf{2 d}$ in the transition state. The computed activation barrier of -3.2 $\mathrm{kcal} / \mathrm{mol}$ for the cycloaddition of $\mathbf{1 a}$ to $\mathbf{2 d}$ is substantially lower than the experimentally determined value of $5.4 \mathrm{kcal} / \mathrm{mol} .{ }^{13}$ There is a dramatic increase in reactivity of $\mathbf{1 d - f}$ toward $\mathbf{2 d}$ as compared to $2 \mathbf{c}\left(\Delta \Delta E^{t}\right.$ ranges from $\left.8-15 \mathrm{kcal} \mathrm{mol}^{-1}\right)$. These differences are caused by large favorable changes in interaction energy and relatively small unfavorable changes in distortion energy of the $2 \mathbf{d}$ series relative to $2 \mathbf{c}$ : average values of $\Delta \Delta E_{d^{t}}$ and $\Delta \Delta E_{i}^{t}$ for cycloadditions of $\mathbf{1 d}-\mathbf{f}$ to $\mathbf{2 c}$ and $\mathbf{2 d}$ are +2.4 and $-8.7 \mathrm{kcal} \mathrm{mol}^{-1}$ respectively. Cycloadditions of $\mathbf{1 c}$ and $\mathbf{1 d}$ to $\mathbf{2 d}$ 
have the same amount of distortion in the TS; thus, the higher reactivity of $\mathbf{1 d}$ relative to $\mathbf{1 c}$ is a result of a $5 \mathrm{kcal} \mathrm{mol}^{-1}$ difference in $\Delta E_{i^{t}}$.

We investigated the relationship between the distortion energies and activation energies as was done previously for other cycloaddition reactions. ${ }^{41-43}$ Houk and Ess discovered a linear correlation between activation energy and distortion energy in the transition states for 18 1,3-dipolar cycloadditions. ${ }^{30}$ Houk and co-workers also observed a similar correlation for 1,4-dihydrogenations and Diels-Alder cycloadditions of aromatic molecules. ${ }^{41}$ Figure 6 shows a plot of $\Delta E^{*}$ versus $\Delta E_{d^{*}}$ for the cycloadditions to ethylene and $\alpha$-chloroacrylonitrile. The observed correlation $\left(r^{2}=0.95\right)$ for cycloadditions to $\mathbf{2 c}$ indicates that the increasing activation barrier is a direct result of increasing distortion energy in the transition state. The cooperative increase in $\Delta E_{i}^{*}$ as shown in Table 1 results in the same correlation $\left(r^{2}=0.95\right)$ between $\Delta E^{*}$ and $\Delta E_{i}^{*}$ for additions to $\mathbf{2 c}$ (Figure $\mathrm{S}-1$ ). Therefore, activation energies for cycloadditions of $\mathbf{1 a}-\mathbf{f}$ to 2c are equally controlled by both $\Delta E_{d^{t}}^{t}$ and $\Delta E_{i^{t}}^{t}$. Similarly, $\Delta E_{d^{t}}^{t}$ and $\Delta E_{i^{t}}^{t}$ exert equal control of $\Delta E^{*}$ for cycloadditions of $\mathbf{1 a}-\mathbf{c}$ to $\mathbf{2 a}$ and $\mathbf{2 b}$ with $r^{2} \sim 0.95-0.99$ (not shown). For cycloadditions to $2 \mathbf{d}$, there is essentially no correlation $\left(r^{2}=0.38\right)$ between $\Delta E^{t}$ and $\Delta E_{d^{t}}^{t}$ for the complete carbene set; however, a correlation does exist for the dihalocarbenes $\mathbf{1 a}-\mathbf{c}\left(r^{2}=1\right)$.

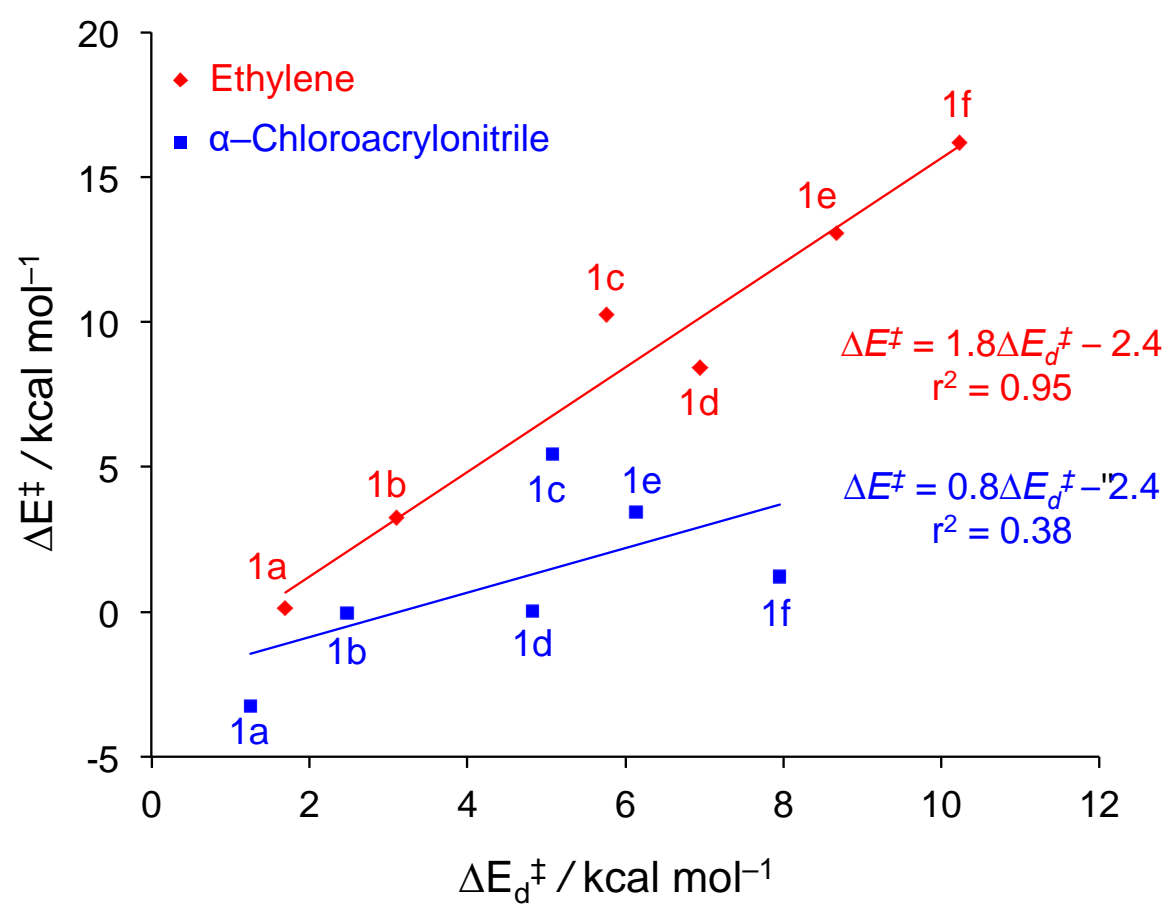

Figure 6. Plot of activation energy versus distortion energy for carbene cycloadditions to ethylene ( $2 \mathrm{c}$; red diamonds) and $\alpha$-chloroacrylonitrile (2d; blue squares). 


\section{Conclusions}

Generally, it is observed that pyramidalization of the alkene carbons is the primary contributor to $\Delta E_{d^{t}}$ in carbene cycloadditions. When compared to dihalocarbenes $\mathbf{1 a}$ and $\mathbf{1 b}$, cycloadditions of 1c to all four alkenes show anomalously unfavorable interaction energies in the transition state. Cycloadditions of $\mathbf{1 b}$ and $\mathbf{1 c}$ with $\mathbf{2 c}$ have essentially the same distortion energy profile, as seen in Figure 4; therefore, the higher $\Delta E^{t}$ of the latter is the result of a later transition state originating from more destabilizing $\Delta E_{i}$ throughout the reaction. $\Delta E_{d^{t}}^{t}$ is constant for the reactions of $\mathbf{1 c}$ and $\mathbf{1 d}$ to $\mathbf{2 d}$, so a more favorable $\Delta E_{i}^{t}$ relative to $\mathbf{1} \mathbf{c}$ is responsible for the higher reactivity of $\mathbf{1 d}$. The cycloaddition of $\mathrm{C}(\mathrm{OMe})_{2}$ to $\alpha$-chloroacrylonitrile shows a $\Delta E_{i}^{t}$ that is more favorable than expected $(\mathbf{1 f}+\mathbf{2 d}$; Table 1$)$ and contributes to a breakdown in the correlation between $\Delta E^{t}$ and $\Delta E_{d^{t}}^{t} / \Delta E_{i^{t}}^{t}$ observed for $\mathbf{2 a - c}$. These results suggest that $(2+1)$ cycloadditions are not only distortion-controlled as are other pericyclic reactions. As represented in Figures 4 and 5, small differences in distortion energies but large differences in interaction energies control the position of the transition state and the reaction rate.

\section{References}

1. Hoffmann, R. J. Am. Chem. Soc. 1968, 90, 1475-1485. http://dx.doi.org/10.1021/ja01008a016

2. Woodward, R. B.; Hoffmann, R. Angew. Chem. Int. Ed. 1969, 8, 781-853 and references cited therein. http://dx.doi.org/10.1002/anie.196907811

3. Moore, W. R.; Moser, W. R.; LaPrade, J. E. J. Org. Chem. 1963, 28, 2200-2205. http://dx.doi.org/10.1021/jo01044a012

4. Bodor, N.; Dewar, M. J. S.; Wasson, J. S. J. Am. Chem. Soc. 1972, 94, 9095-9102. http://dx.doi.org/10.1021/ja00781a018

5. Hoffmann, R.; Hayes, D. M.; Skell, P. S. J. Phys. Chem. 1972, 76, 664-669. http://dx.doi.org/10.1021/j100649a010

6. Kollmar, H. J. J. Am. Chem. Soc. 1978, 100, 2660-2664. http://dx.doi.org/10.1021/ja00477a015

7. Joo, H.; Kraka, E.; Quapp, W.; Cremer, D. Mol. Phys. 2007, 105, 2697-2717 and references cited therein. http://dx.doi.org/10.1080/00268970701620677

8. Rondan, N. G.; Houk, K. N.; Moss, R. A. J. Am. Chem. Soc. 1980, 102, 1770-1776. http://dx.doi.org/10.1021/ja00526a002

9. Moss, R. A.; Wang, L.; Zhang, M.; Skalit, C.; Krogh-Jespersen, K. J. Am. Chem. Soc. 2008, 130, 5634-5635. http://dx.doi.org/10.1021/ja8005226

PMid:18393413 
10. Moss, R. A.; Wang, L.; Krogh-Jespersen, K. J. Am. Chem. Soc. 2009, 131, 2128-2130. http://dx.doi.org/10.1021/ja809370j

PMid:19173648

11. Moss, R. A.; Wang, L.; Zhang, M. Org. Lett. 2008, 10, 4045-4048.

http://dx.doi.org/10.1021/ol801575v

PMid:18729368

12. Moss, R. A.; Zhang, M.; Krogh-Jespersen, K. Org. Lett. 2010, 12, 3476-3479.

http://dx.doi.org/10.1021/ol1013119

PMid:20597479

13. Zhang, M.; Moss, R. A.; Thompson, J.; Krogh-Jespersen, K. J. Org. Chem. 2012, 77, 843850.

http://dx.doi.org/10.1021/jo2023558

PMid:22204738

14. Ess, D. H.; Houk, K. N. J. Am. Chem. Soc. 2007, 129, 10646-10647.

http://dx.doi.org/10.1021/ja0734086

PMid:17685614

15. van Zeist, W.-J.; Bickelhaupt, F. M. Org. Biomol. Chem. 2010, 8, 3118-3127.

http://dx.doi.org/10.1039/b926828f

PMid:20490400

16. Zhao, Y.; Truhlar, D. G. Theor. Chem. Account 2008, 120, 215-241.

http://dx.doi.org/10.1007/s00214-007-0310-x

17. Frisch, M. J. et al. Gaussian 09, revision C-01; Gaussian, Inc.: Wallingford, CT, 2009 (see complete reference in the Supporting Information).

18. Fukui, K. J. Phys. Chem. 1970, 74, 4161-4163.

http://dx.doi.org/10.1021/j100717a029

19. Deng, L; Ziegler, T. Int. J. Quantum Chem. 1994, 52, 731-765.

http://dx.doi.org/10.1002/qua.560520406

20. Moss, R. A.; Lawrynowicz, W.; Turro, N. J.; Gould, I. R.; Cha, Y. J. Am. Chem. Soc. 1986, 108, 7028-7032.

http://dx.doi.org/10.1021/ja00282a030

21. Houk, K. N.; Rondan, N. G.; Mareda, J. J. Am. Chem. Soc. 1984, 106, 4291-4293. http://dx.doi.org/10.1021/ja00327a052

22. Houk, K. N.; Rondan, N. G.; Mareda, J. Tetrahedron 1985, 41, 1555-1563. http://dx.doi.org/10.1016/S0040-4020(01)96395-1

23. Turro, N. J.; Lehr, G. F.; Butcher, J. A., Jr.; Moss, R. A.; Guo, W. J. Am. Chem. Soc. 1982, 104, 1754-1756.

http://dx.doi.org/10.1021/ja00370a059

24. Moss, R. A.; Perez, L. A.; Turro, N. J.; Gould, I. R.; Hacker, N. P. Tetrahedron Lett. 1983, 24, 685-688.

http://dx.doi.org/10.1016/S0040-4039(00)81498-7

25. Gould, I. R.; Turro, N. J.; Butcher, J. A., Jr., Doubleday, C. E., Jr., Hacker, N. P.; Lehr, G. F.; Moss, R. A.; Cox, D. P.; Guo, W.; Munjal, R. C.; Perez, L. A. Fedorynski, M. Tetrahedron 
1985, 41, 1587-1600.

http://dx.doi.org/10.1016/S0040-4020(01)96399-9

26. Liu, M. T. H. J. Chem. Soc., Chem. Commun. 1985, 982-985.

27. Liu, M. T. H.; Subramanian, R. Tetrahedron Lett. 1985, 26, 3071-3074.

http://dx.doi.org/10.1016/S0040-4039(00)98621-0

28. Tomioka, H.; Hayashi, N.; Izawa, Y.; Liu, M. T. H. J. Am. Chem. Soc. 1984, 106, 454-456. http://dx.doi.org/10.1021/ja00314a051

29. Liu, M. T. H.; Subramanian, R. J. Chem. Soc., Chem. Commun. 1984, 1062-1064.

30. Ess, D. H.; Houk, K. N. J. Am. Chem. Soc. 2008, 130, 10187-10198. http://dx.doi.org/10.1021/ja800009z PMid:18613669

31. Huisgen, R. In 1,3-Dipolar Cycloaddition Chemistry; Padwa, A., Ed.; John Wiley and Sons: New York, 1984; Vol. 1 and references cited therein.

32. Houk, K. N. In 1,3-Dipolar Cycloaddition Chemistry; Padwa, A., Ed.; John Wiley and Sons: New York, 1984; Vol. 2 and references cited therein.

33. Houk, K. N.; Sims, J.; Duke, R. E., Jr.; Strozier, R. W.; George, J. K. J. Am. Chem. Soc. 1973, 95, 7287-7301. http://dx.doi.org/10.1021/ja00803a017

34. Houk, K. N.; Sims, J.; Watts, C. R.; Luskus, L. J. J. Am. Chem. Soc. 1973, 95, 7301-7315. http://dx.doi.org/10.1021/ja00803a018

35. Bastide, J.; Ghandour, W. E.; Henri-Rousseau, O. Tetrahedron Lett. 1972, 13, 4225-4228. http://dx.doi.org/10.1016/S0040-4039(01)94281-9

36. Fernandez, I.; Bickelhaupt, F. M.; Cossio, F. P. J. Org. Chem. 2011, 76, 2310-2314. http://dx.doi.org/10.1021/jo102572x PMid:21388217

37. Fernandez, I.; Bickelhaupt, F. M. J. Comput. Chem. 2012, 33, 509-516. http://dx.doi.org/10.1002/jcc. 22877 PMid:22144106

38. Fernandez, I.; Bickelhaupt, F. M.; Cossio, F. P. Chem. Eur. J. 2009, 15, 13022-13032. http://dx.doi.org/10.1002/chem.200902024 PMid:19852009

39. Bento, P. A.; Bickelhaupt, F. M. J. Org. Chem. 2008, 73, 7290-7299. http://dx.doi.org/10.1021/jo801215z PMid:18690745

40. Bickelhaupt, F. M. J. Comput. Chem. 1999, 20, 114-128. http://dx.doi.org/10.1002/(SICI)1096-987X(19990115)20:1<114::AID-JCC12>3.0.CO;2-L

41. Hayden, A. E.; Houk, K. N. J. Am. Chem. Soc. 2009, 131, 4084-4089. http://dx.doi.org/10.1021/ja809142x PMid:19256544

42. Liang, Y.; Mackey, J. L.; Lopez, S. A.; Liu, F.; Houk, K. N. J. Am. Chem. Soc. 2012, 134, 17904-17907. http://dx.doi.org/10.1021/ja809142x 
PMid:19256544

43. Lopez, S. A.; Houk, K. N. J. Org. Chem. 2013, 78, 1778-1783.

http://dx.doi.org/10.1021/jo301267b

PMid:22764840 